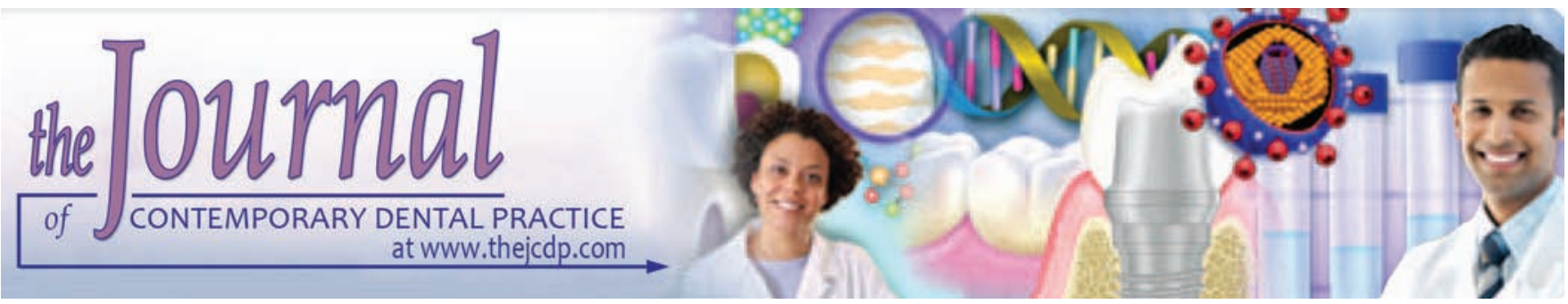

\title{
Preserving the Bone Profile in Anterior Maxilla using an Equine Cortical Bone Membrane and an Equine Enzyme-treated Bone Graft: A Case Report with 5-year Follow-up
}

${ }^{1}$ Danilo A Di Stefano, ${ }^{2}$ Umberto Garagiola, ${ }^{3}$ Mirko A Bassi

\begin{abstract}
Aim: This study aimed to report a well-succeeded use of equine enzyme-deantigenic cortical membrane and bone granules for guided bone regeneration (GBR) in the esthetic zone concomitant with implant placement.
\end{abstract}

Background: In the anterior maxilla, where patients typically have the highest expectations for implant-supported restorations, bone resorption in the wake of tooth loss often leads to a lack of soft tissue support and ultimately to unsatisfactory esthetic results. Buccal bone augmentation at the time of implant placement has thus become common. This is usually accomplished following GBR principles and employing membranes made from various materials to serve as a barrier between the soft tissue and graft material. One of the more recently introduced membrane materials is made from thin, flexible equine cortical bone, i.e., rendered nonantigenic in an enzymatic process that preserves native bone collagen.

Case report: This report describes the treatment of a patient who received an equine enzyme-deantigenic graft and membrane in conjunction with placement of an implant in the right maxillary lateral incisor site.

Conclusion: After 5 years of follow-up, the patient was very satisfied with her appearance. A cone-beam computed tomography scan showed that the peri-implant bone levels and ridge thickness had been maintained, and the cortical layer in the pristine ridge had also undergone remodeling.

\footnotetext{
${ }^{1}$ Department of Dentistry, Vita e Salute San Raffaele University Milan, Italy

${ }^{2}$ Department of Biomedical, Surgical and Dental Sciences University of Milan, Milan, Italy

${ }^{3}$ Private Practitioner, Rome, Italy
}

Corresponding Author: Danilo A Di Stefano, Department of Dentistry, Vita e Salute San Raffaele University, Milan, Italy Phone: +390248705703, e-mail: distefano@centrocivitali.it
Clinical significance: Guided bone regeneration with the concomitant use of enzyme-deantigenic membrane and graft is a valuable and suitable option for effective implant-supported prosthetic rehabilitation in the esthetic zone.

Keywords: Cortical bone membrane, Guided bone regeneration, Horizontal ridge augmentation, Xenograft.

How to cite this article: Di Stefano DA, Garagiola U, Bassi MA. Preserving the Bone Profile in Anterior Maxilla using an Equine Cortical Bone Membrane and an Equine Enzyme-treated Bone Graft: A Case Report with 5-year Follow-up. J Contemp Dent Pract 2017;18(7):614-621.

Source of support: The work was partially sponsored by Bioteck S.p.A. which donated the bone granules and the cortical bone membrane. Data belonged to the authors and by no means did the manufacturer interfere with the conduct of the case or the publication of its results.

Conflict of interest: None

\section{BACKGROUND}

Implant-supported prosthetic rehabilitation in the esthetic zone presents one of the hardest challenges for oral surgeons, as several factors may compromise the final esthetic result. Among these, bone resorption caused by a previous tooth loss or extraction ${ }^{1}$ and the consequent lack of soft tissue support may lead to unsatisfying results. A second issue is how the choices undertaken at the moment of implant placement will condition the preservation of the esthetic result over time. For this purpose, the stability of both the hard and soft tissues is of paramount importance. The two are interconnected, as only a bone volume, i.e., stable over time may guarantee adequate support to soft tissues and preservation of their long-term stability.

Even when the dimensions of the alveolar bone are sufficient to allow for placement of osseointegrated fixtures, buccal bone augmentation is often advised to 

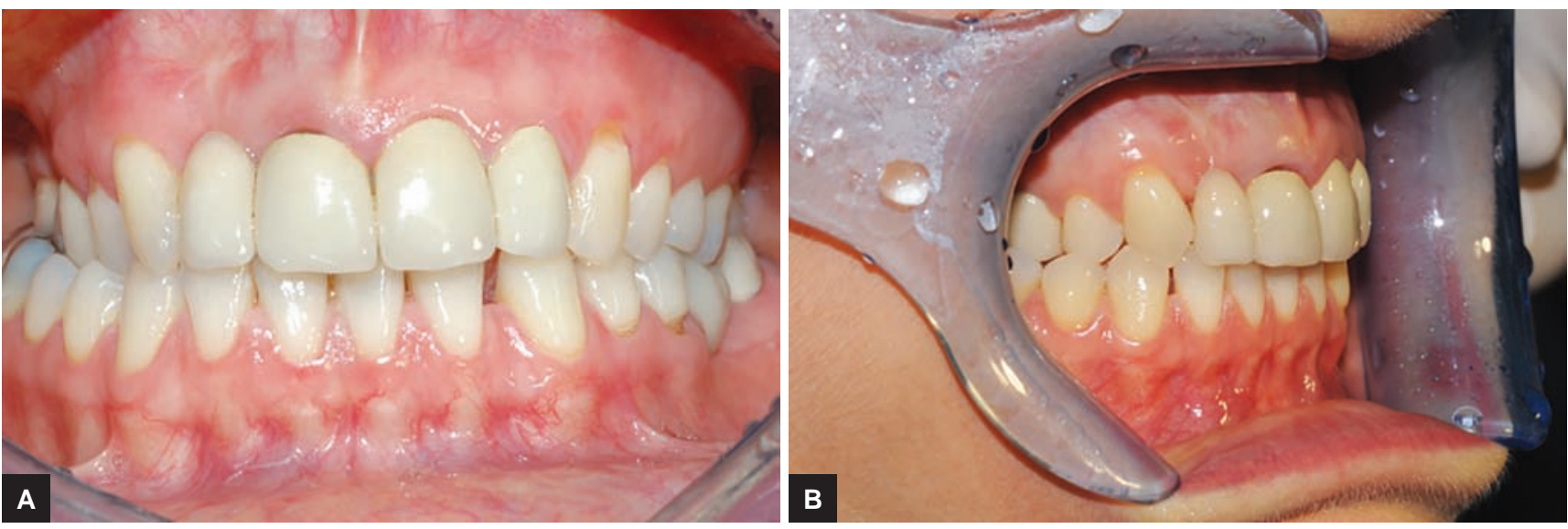

Figs 1A and B: Appearance of the patient's prosthesis with esthetic concerns

achieve a stable and satisfying esthetic restorative result. Augmentation at the time of implant placement has thus become a common technique for enhancing implant survival and success or increasing soft tissue support in demanding esthetic cases. ${ }^{2,3}$ When the available bone volume enables implant placement, buccal bone augmentation is usually performed following the principles of guided bone regeneration $(\mathrm{GBR})^{4,5}$ (i.e., interposing a barrier between the soft tissue and graft material that works as an osteoconductive support for bone regeneration). The first such barriers were nonresorbable and had to be removed after healing of the grafted site. ${ }^{6,7}$ Later, resorbable membranes were introduced that allowed effective bone regeneration while reducing the complication rates associated with membrane exposure and avoiding a second surgery for barrier removal. Membranes currently used to perform GBR interventions range from resorbable collagen or synthetic membranes ${ }^{8,9}$ to nonresorbable expanded or high-density polytetrafluoroethylene (PTFE) barriers ${ }^{10}$ to nonresorbable titanium meshes. ${ }^{11}$ Whatever the material used and its resorption properties, barrier membranes for GBR still must meet the five criteria stated by Scantlebury in $1993,{ }^{12}$ i.e., tissue integration, cell occlusivity, clinical manageability, space making, and biocompatibility.

Recently, an equine bone membrane was made available in the market that consists of a thin layer of flexible cortical bone. For its manufacture, equine cortical bone is first made nonantigenic by the use of digestive enzymes that eliminate equine antigens. Then, the bone is made thin by mechanical abrasion. Finally, the bone sheet undergoes partial demineralization to make it flexible. The enzymatic process preserves bone collagen in its native form. In a previous case, such a membrane was found to allow effective bone regeneration when horizontal bone augmentation was performed in combination with enzyme-deantigenic bone granules. ${ }^{13}$ When a portion of the membrane was retrieved 3.5 months later, histologic examination showed that it was still occlusive, even though it was undergoing osteoclastic remodeling. Preservation of occlusivity for some months, if confirmed, would make this membrane a possible candidate for effective GBR aimed at preserving bone profiles in the esthetic zone concomitant with implant placement.

The present report describes a case in which this kind of membrane was used in association with equine enzymedeantigenic bone granules for this specific application.

\section{CASE REPORT}

The patient was a 45-year-old female with a noncontributory medical history seeking to improve the esthetics of her anterior upper maxilla. She had lost her right maxillary lateral incisor and had been previously rehabilitated with a four-unit bridge supported by the remaining three incisors. However, the patient was unsatisfied with the appearance of the soft tissue contours around the bridge, the gaps between the soft tissue and the prosthesis, and the unnatural appearance of the ceramics (Fig. 1), which did not match the natural teeth.

Clinical and radiographic examination revealed a horizontal defect of the alveolar ridge at the missing lateral incisor site (Figs 2 and 3). A one-step procedure

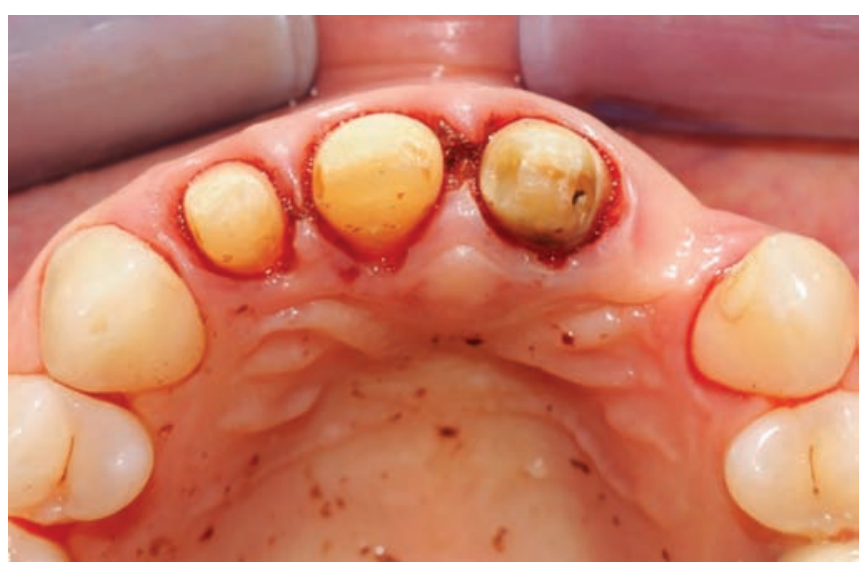

Fig. 2: Clinical appearance after removal of the bridge. Preparation of the remaining incisors was suboptimal, and a buccal bone deficiency was evident at the site of the missing right lateral incisor 


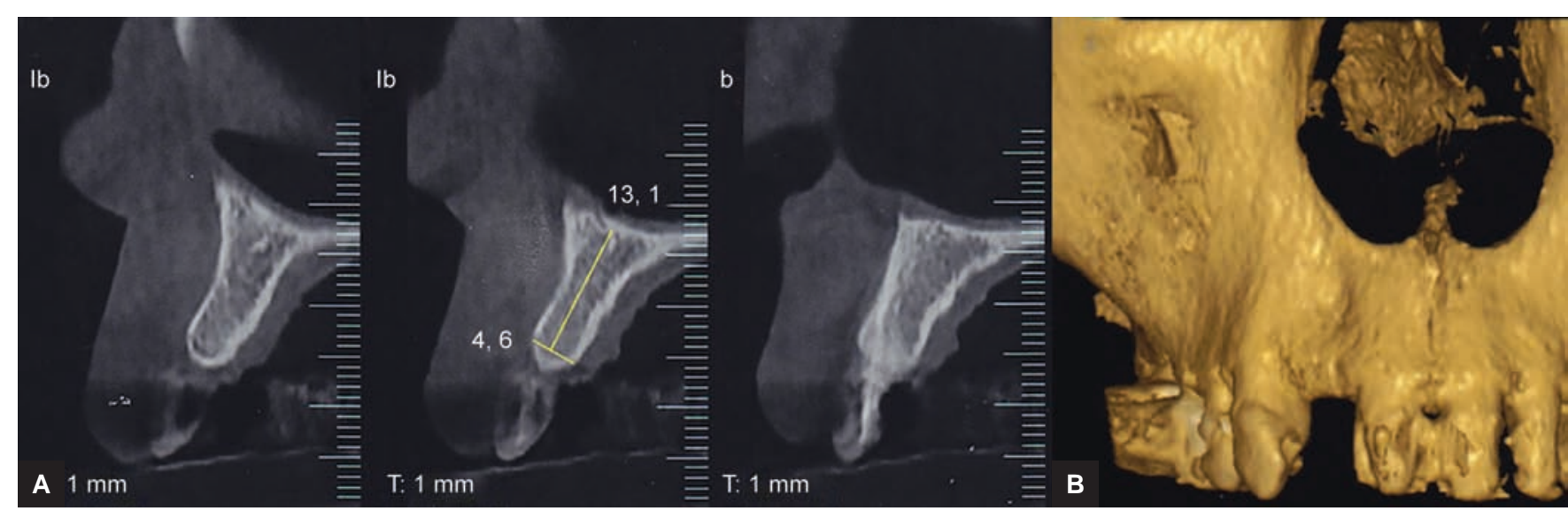

Figs $3 \mathrm{~A}$ and B: Cone beam computed tomographic scan confirmed the presence of buccal bone defect

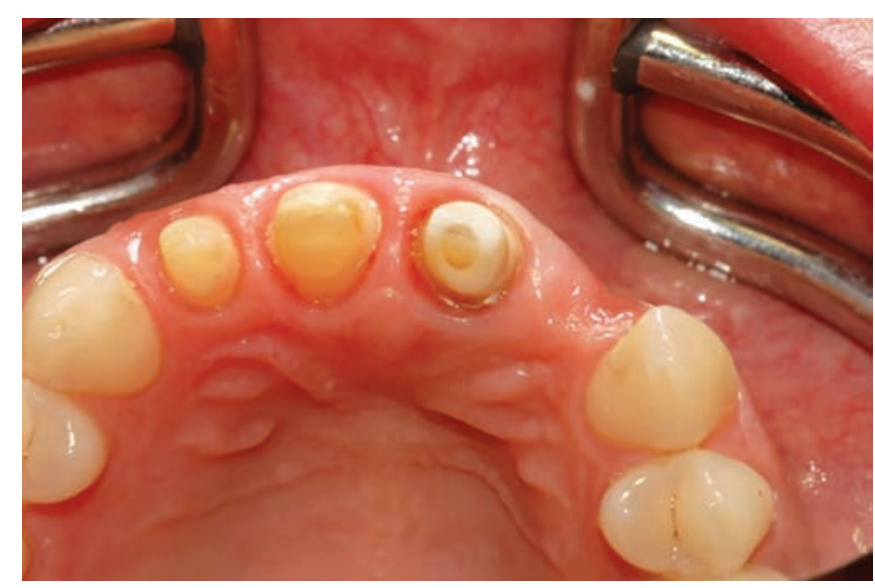

Fig. 4: Remaining incisors were prepared to later support single crowns as part of the rehabilitation plan

that included placement of an implant there along with simultaneous grafting of the buccal side of ridge was developed with the aim of rehabilitating the patient with four single crowns supported by the implant and the three remaining incisors. The patient provided informed consent, and the three incisors were prepared for later crown restoration (Fig. 4).

Based on the cone beam computed tomographic (CBCT) scans and an implant positioning design that was preplanned digitally, a surgical template was fabricated. This was sterilized in an autoclave some days before the surgery. For antibiotic prophylaxis, 2 gm of amoxicillin/ clavulanic acid (Augmentin, Glaxo-SmithKline, Verona, Italy) was administered 1 hour before the surgery and then every 12 hours for 8 days. The patient also rinsed for 2 minutes with chlorhexidine $0.20 \%$ mouth rinse (Corsodyl, Glaxo-SmithKline) and received $100 \mathrm{mg}$ of a nonsteroidal anti-inflammatory drug (Aulin, Roche, Milano, Italy). Local anesthetic was administered by means of infiltration into the oral mucosa with $1 \%$ articaine with epinephrine 1:100,000 (Molteni Dental, Milano, Italy).

A mid-crestal full-thickness incision was created within the keratinized mucosa of the edentulous ridge, extending it partially to the right central incisor and cuspid through an intrasulcular incision; an envelope flap was elevated. The implant site was prepared by drilling with the surgical guide and then using an osteotome. Then, a cylindrical $3.3 \mathrm{~mm} \times 13 \mathrm{~mm}$ implant (Xive, Dentsply, York, PA, USA) was placed (Fig. 5). Its alignment was verified using a paralleling pin.

An equine cortical bone membrane (Osteoxenon ${ }^{\circledR}$ Cortical membrane, $25 \mathrm{~mm} \times 25 \mathrm{~mm} \times 0.2 \mathrm{~mm}$, Bioteck, Arcugnano, Italy, Fig. 6A) was cut to the desired shape (Fig. 6B), hydrated with sterile saline, and inserted between the flap and the ridge. The gap between the membrane and the ridge was filled with equine enzymeprocessed 0.5 to $1.0 \mathrm{~mm}$ bone granules (Osteoxenon ${ }^{\circledR} \mathrm{Mix}$ Bone Granules, Bioteck, Arcugnano, Italy) (Figs 7A and B). As the membrane was already stabilized by the flap, no pins or screws were used to secure it to the alveolar ridge.

The flap was closed using nonresorbable suture material (Monomyd 4-0/5-0 Polyamide Monofilament Suture, Butterfly, Cavenago, Italy) (Fig. 7C), leaving the implant submerged. The patient wore a provisional restoration that was supported by the incisors for the next 4 months. Then, under the same antibiotic prophylaxis previously described, the implant was uncovered, and a healing screw was placed to allow for proper soft tissue conditioning. Nonresorbable sutures (Monomyd 4-0/5-0 Polyamide Monofilament Suture, Butterfly, Cavenago, Italy) (Fig. 8) were placed and removed 6 days later. Soft tissue conditioning occurred over the ensuing 4 months (Fig. 9), at which point the patient was rehabilitated definitively (Fig. 10). She returned for follow-up assessment every 6 months for the next 5 years. At that point, she needed replacement of an old posterior maxillary bridge, and another CBCT scan was required. This enabled assessment of the bone volume that corresponded to the earlier augmentation procedure.

The appearance of the rehabilitation was still quite satisfactory (Figs 11A and B), with no gingival recession 

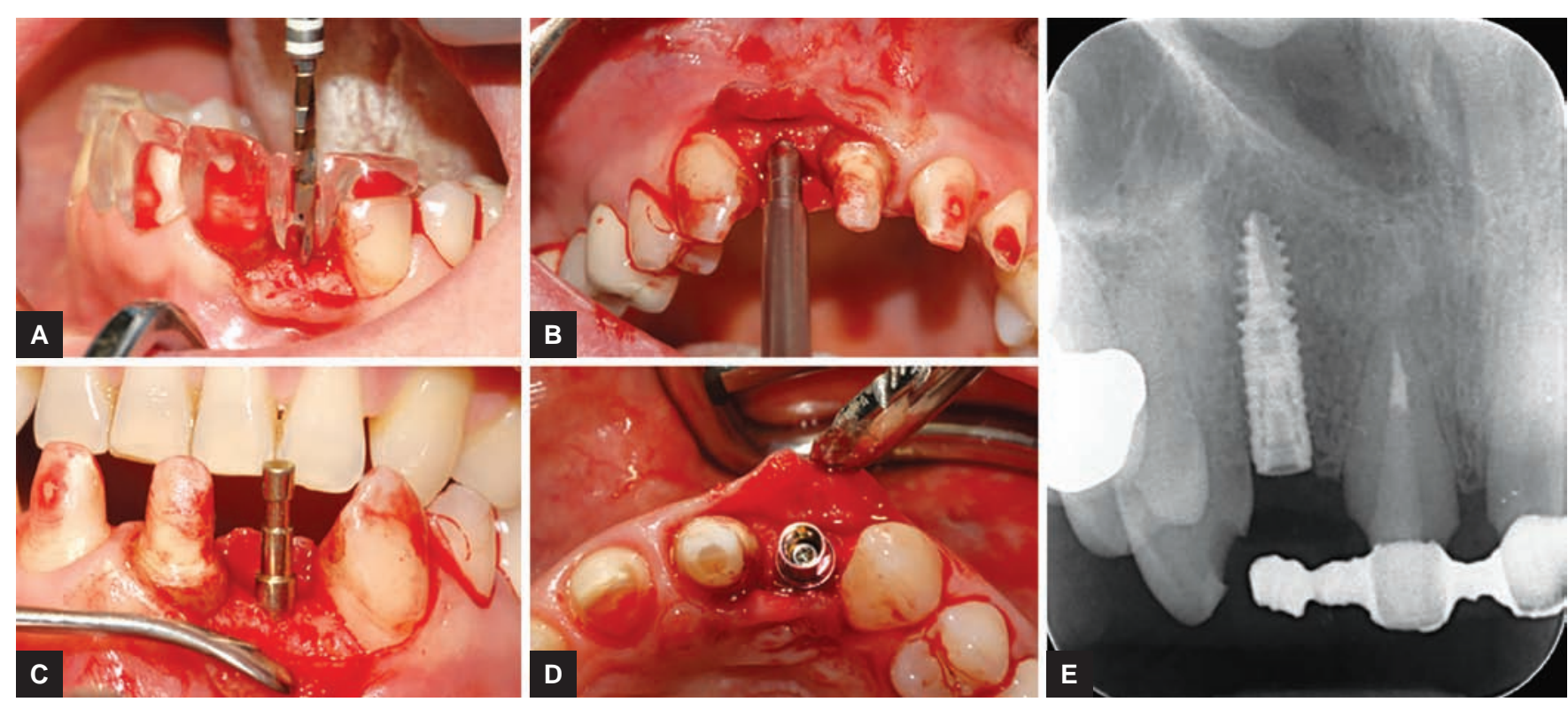

Figs 5A to E: Implant placement. Site was prepared with the aid of a surgical guide, drills and an osteotome
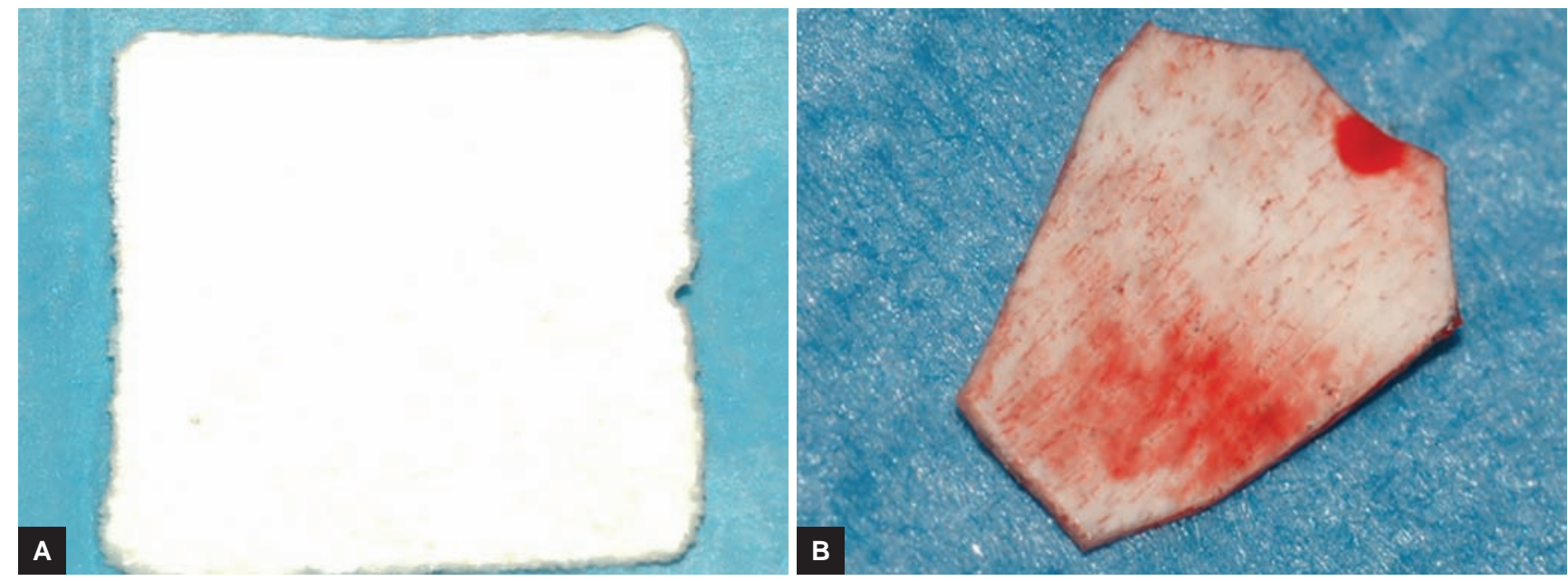

Figs 6A and B: The equine cortical bone membrane. The membrane is a $25 \mathrm{~mm} \times 25 \mathrm{~mm} \times 0.2 \mathrm{~mm}$ cortical flexible bone sheet: (A) before cutting and hydration; and (B) after cutting but before hydration and placement
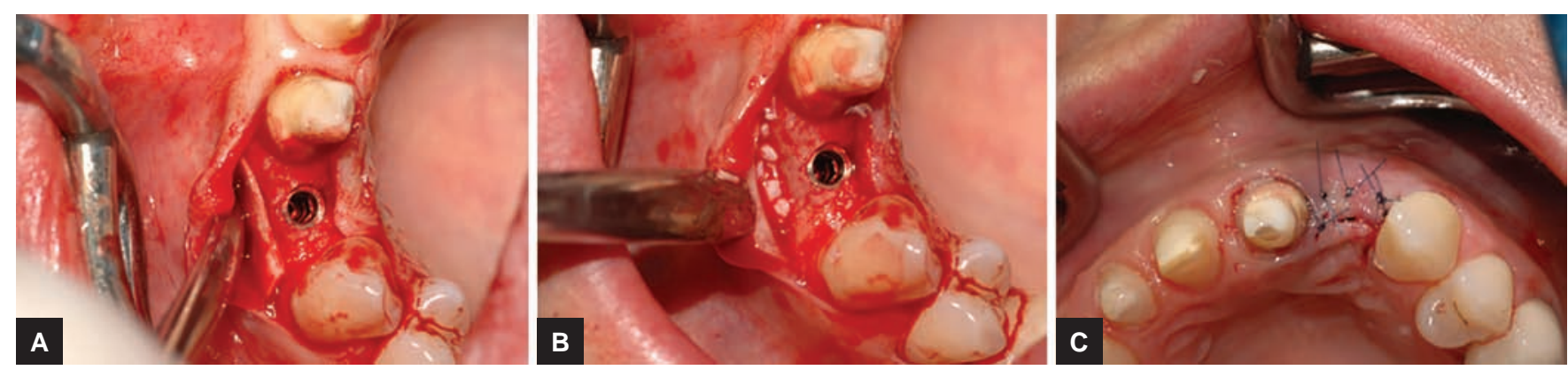

Figs 7A to C: Membrane was placed under the flap, and gap between membrane and ridge was filled with equine enzyme-deantigenic bone granules

evident. The peri-implant bone levels also had been maintained (Fig. 11C). The CBCT scan showed that no ridge thickness had been lost at the recipient site and that a new cortical layer could be observed, while the cortical layer in the pristine ridge had undergone remodeling (Fig. 12).

\section{DISCUSSION}

The basic principle of GBR involves using membranes to isolate the blood clot and biomaterial and protect them from connective tissue. The isolated secluded space can then be invaded by bone-forming cells, and bone 


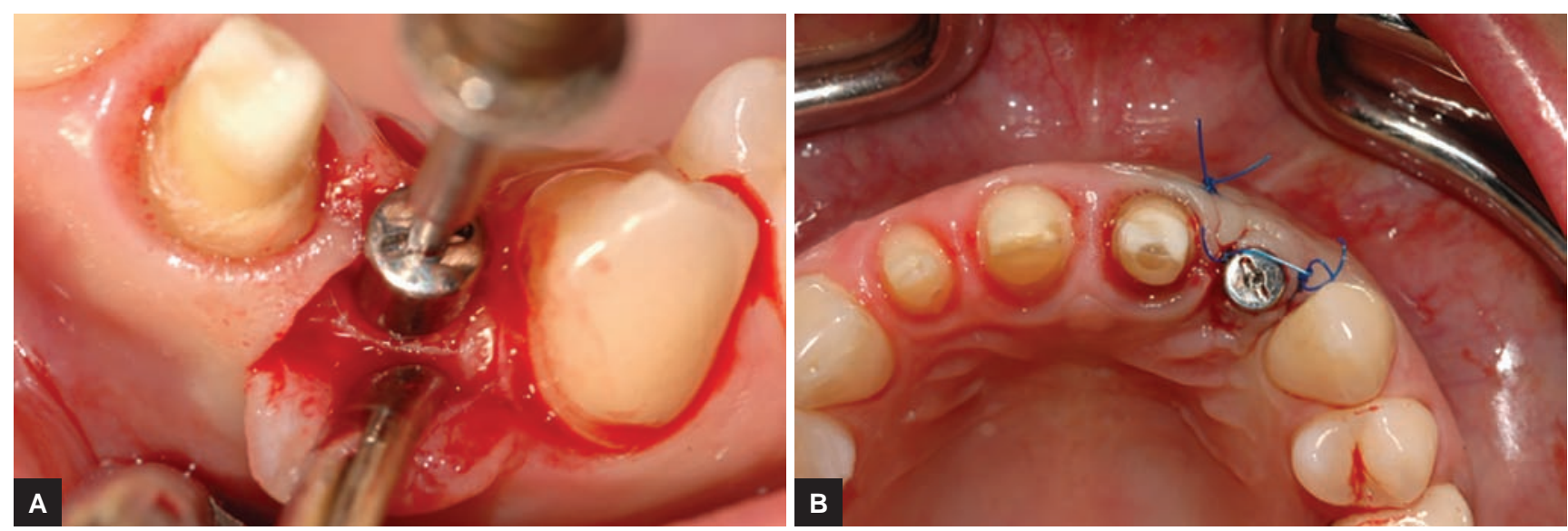

Figs 8A and B: Uncovering of the implant. Healing screw was placed to allow proper soft tissue conditioning

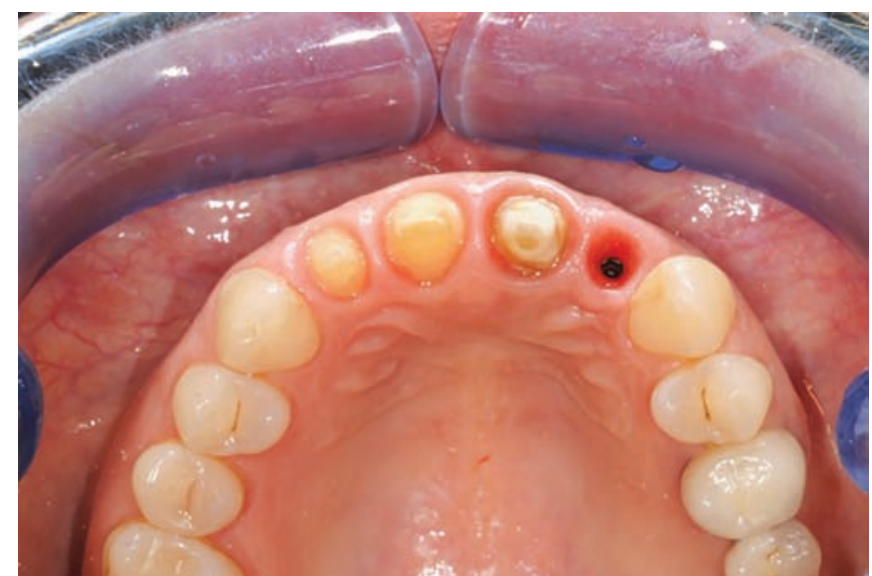

Fig. 9: Soft tissue conditioning

formation can occur. In addition, the barrier membrane helps to stabilize the graft and prevent micromovement that could hinder the bone regeneration process.

To work properly, the barrier must meet some basic requirements. ${ }^{12,14}$ First, it must be biocompatible, i.e., completely tolerated by the host tissue. Second, it should maintain a suitable space for tissue ingrowth while providing adequate support to the covering tissue. This requires a certain stiffness, which may be achieved by modulating the membrane thickness and/or using materials with proper physical properties. However, the membrane also should have enough malleability so that it can be shaped to the specific geometry needed for each
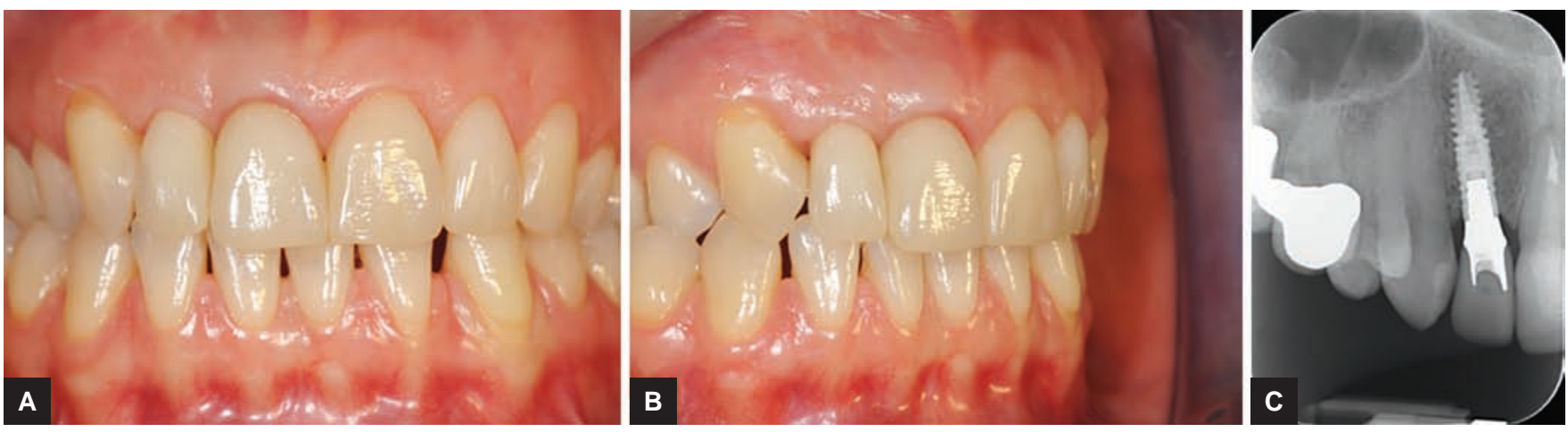

Figs $10 \mathrm{~A}$ to $\mathrm{C}$ : Final restoration
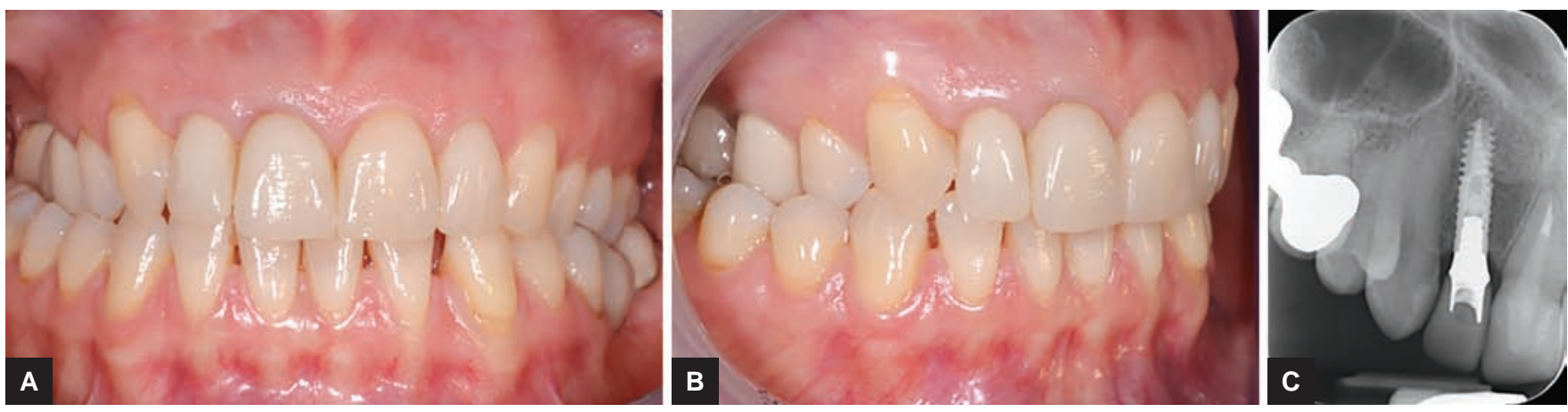

Figs 11A to C: Esthetic appearance of the prosthesis was still optimal at the 5-year follow-up visit. The intraoral radiograph showed no signs of peri-implant bone resorption 


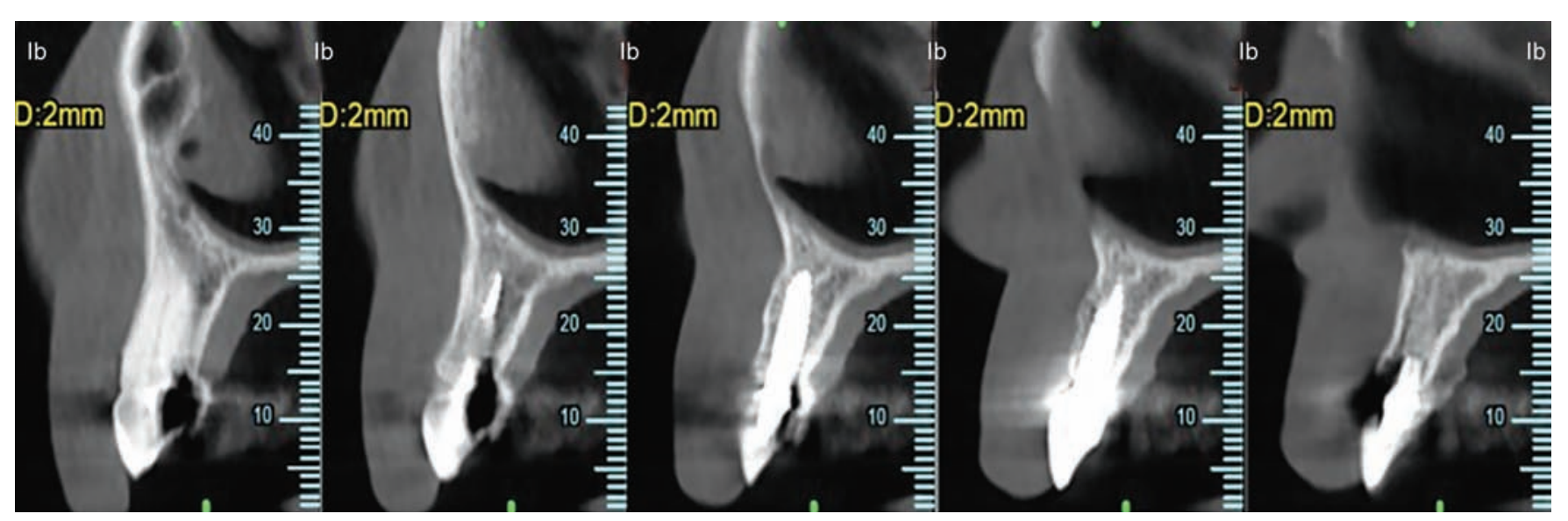

Fig. 12: Five-year follow-up СВСТ scan. Bone volume at the implant and graft site was preserved. While the graft had undergone remodeling, a new cortical layer could be observed where the cortical membrane was placed (sections 25 and 26)

reconstruction. In addition, the barrier should guarantee occlusivity to avoid fibrous tissue formation. The main factor conditioning the degree of membrane occlusivity is porosity, a feature that may not strictly depend on the membrane material. Porosity has been shown to play a key role in preventing cell invasion and allowing the diffusion of fluids, oxygen, nutrients, and growth factors. ${ }^{15,16}$ The membrane also must integrate with the host tissue, i.e., its borders must adapt to the original bone adjacent to the defect(s) and create a seal capable of preventing fibrous connective tissue entry into the defect site. ${ }^{17}$

The membrane used in the present study is made of cortical bone, i.e., the same type of tissue that constitutes the natural outer layer of the alveolar ridge. Its stiffness and malleability give it excellent handling properties. In the present case, it provided sufficient rigidity to prevent collapsing, but it was easily adapted to make its borders stick to the bone adjacent to the defect. Cortical bone porosity is determined also by the structural and functional connections it has with the periosteum; it also modulates the exchange of nutrients and fluids at the periosteum-bone interface. ${ }^{18}$ It is, therefore, reasonable to assume that a thin cortical bone sheet might display optimal porosity for guaranteeing both fluid and nutrient with the underlying graft exchange while preventing soft tissue cells from invading the grafted site.

Cortical bone grafts display certain properties when both the graft and recipient sites may undergo osteoclastic remodeling and consequent replacement with newly formed bone; in this case, a continuum is created between the two. ${ }^{19,20}$ This supports the hypothesis that, being made of cortical bone and being susceptible to osteoclastic remodeling, the membrane used in the present study could have incorporated at the bone borders adjacent to the graft site, creating an effective seal and preventing soft tissue invasion. Indeed, the results of the present study show that the cortical bone membrane allowed bone regeneration and remodeling in the graft volume to occur. This is consistent with previous studies by Lopez et $\mathrm{al}^{21}$ and Wachtel et $\mathrm{al}^{22}$ who observed that a xenogeneic cortical lamina, even if thicker (0.5-3 mm), was capable of providing optimal support to a granular bone graft in a technique mimicking the Khoury bone block approach for lateral augmentation. ${ }^{23}$

Remodeling properties of the cortical membrane used in the present study might be ascribed to the specific enzymatic treatment it undergoes to make it nonantigenic. That process preserves bone collagen in its native state, which should allow for an improved bone regeneration process, given collagen's well-known biological properties. ${ }^{24-31}$ Indeed, osteoclasts cultured over such equine, enzymatically deantigenated, and collagenpreserving bone substitutes have significantly higher adhesion and activity than that found for osteoclasts grown over collagen-free, totally deproteinized bovine bone. ${ }^{32,33}$ When sites augmented with equine bone alone were compared with others augmented with the same material added to autogenous bone, immunohistochemical tests showed no differences between the two regarding the expression of some biochemical markers of bone regeneration. ${ }^{34}$

Partially demineralized equine cancellous blocks also have been performed successfully in lateral ridge augmentation without any bone loss detectable on CT scans with respect to the grafted volume. ${ }^{35}$ Yet such remodeling properties do not explain completely the other noteworthy observations of the present study, i.e., that the patient's pristine cortical bone layer underwent remodeling and a new cortical bone layer could be observed on the regenerated buccal ridge side. Similar behavior was observed by the author when a rigid equine bone block, again made nonantigenic using enzymes and preserving the native bone collagen, was grafted as an onlay below an expanded PTFE membrane to perform 
a horizontal augmentation of an atrophic ridge. ${ }^{36}$ Both the effectiveness of the cortical membrane used in the present study and the pristine cortical layer remodeling and substitution described should be the object of further clinical studies.

\section{CONCLUSION}

The equine cortical bone membrane used in the present case allowed for successful GBR in the horizontal augmentation of a partially atrophic ridge. Both its effectiveness and its remodeling properties should be subjected to further investigations.

\section{CLINICAL SIGNIFICANCE}

With the increasing esthetic and functional demands of the patient, buccal bone augmentation has become a common technique for implant placement and survival, while presenting a challenge to oral surgeon. The equine enzyme-deantigenic membrane placed with bone granules in accordance with GBR principle appears as a promising option for effective implant-supported prosthetic rehabilitation in the esthetic zone.

\section{REFERENCES}

1. Araújo MG, Lindhe J. Dimensional ridge alterations following tooth extraction. An experimental study in the dog. J Clin Periodontol 2005 Feb;32(2):212-218.

2. Belser UC, Schmid B, Higginbottom F, Buser D. Outcome analysis of implant restorations located in the anterior maxilla: a review of the recent literature. Int J Oral Maxillofac Implants 2004 Feb;19 (Suppl):30-42.

3. Aghaloo TL, Moy PK. Which hard tissue augmentation techniques are the most successful in furnishing bony support for implant placement? Int J Oral Maxillofac Implants 2007;22 (Suppl):49-70.

4. Nyman S, Lang NP, Buser D, Bragger U. Bone regeneration adjacent to titanium dental implants using guided tissue regeneration: a report of two cases. Int J Oral Maxillofac Implants 1990 Spring;5(1):9-14.

5. Tinti C, Parma-Benfenati S, Polizzi G. Vertical ridge augmentation: What is the limit? Int J Periodontics Restorative Dent 1996 Jun;16(3):220-229.

6. Gotfredsen K, Warrer K, Hjørting-Hansen E, Karring T. Effect of membranes and porous hydroxyapatite on healing in bone defects around titanium dental implants. An experimental study in monkeys. Clin Oral Implants Res 1991 Oct;2(4):172-178

7. Jovanovic SA, Spiekermann H, Richter EJ. Bone regeneration around titanium dental implants in dehisced defect sites: A clinical study. Int J Oral Maxillofac Implants 1992 Summer;7(2):2332-2345.

8. Garg A. Barrier membranes-materials review, Part I of II. Dent Implantol Update 2011 Sep;22(9):61-64.

9. Stoecklin-Wasmer C, Rutjes AW, da Costa BR, Salvi GE, Jüni P, Sculean A. Absorbable collagen membranes for periodontal regeneration: a systematic review. J Dent Res 2013 Sep;92(9):773-781.
10. Carbonell JM, Martín IS, Santos A, Pujol A, Sanz-Moliner JD, Nart J. High-density polytetrafluoroethylene membranes in guided bone and tissue regeneration procedures: a literature review. Int J Oral Maxillofac Surg 2014 Jan;43(1):75-84.

11. Rasia-dal Polo M, Poli PP, Rancitelli D, Beretta M, Maiorana C. Alveolar ridge reconstruction with titanium meshes: a systematic review of the literature. Med Oral Patol Oral Cir Bucal 2014 Nov;19(6):e639-e646.

12. Scantlebury TV. 1982-1992: a decade of technology development for guided tissue regeneration. J Periodontol 1993 Nov;64(Suppl 11):1129-11237.

13. DiStefano DA, Vinci R, Cremaschini G, PagnuttiS, Gherlone EF. GBR-based restoration of peri-implant defect with an equine flexible cortical bone membrane and heterologous equine bone. Ital Oral Surg 2011 Feb;10(1):5-14.

14. Rakhmatia YD, Ayukawa Y, Furuhashi A, Koyano K. Current barrier membranes: titanium mesh and other membranes for guided bone regeneration in dental applications. J Prosthodont Res 2013 Jan;57(1):3-14.

15. Salzmann DL, Kleinert LB, Berman SS, Williams SK. The effects of porosity on endothelialization of ePTFE implanted in subcutaneous and adipose tissue. J Biomed Mater Res 1997 Mar;34(4):463-476.

16. Lundgren AK, Sennerby L, Lundgren D, Taylor A, Gottlow J, Nyman S. Bone augmentation at titanium implants using autologous bone grafts and a bioresorbable barrier. An experimental study in the rabbit tibia. Clin Oral Implants Res 1997 Apr;8(2):82-89.

17. Kostopoulos L, Karring T. Augmentation of the rat mandible using guided tissue regeneration. Clin Oral Implants Res 1994 Jun;5(2):75-82.

18. Allen MR, Hock JM, Burr DB. Periosteum: biology, regulation, and response to osteoporosis therapies. Bone 2004 Nov;35(5):1003-1012.

19. Garbuz DS, Masri BA, Czitrom AA. Biology of allografting. Orthop Clin North Am 1998 Apr;29(2):199-204.

20. Schenk RK, Buser D. Osseointegration: a reality. Periodontol 20001998 Jun;17:22-35.

21. Lopez MA, Andreasi Bassi M, Confalone L, Carinci F. Regeneration of atrophic crestal ridges with resorbable lamina: technical note. J Biol Regul Homeost Agents 2015 Sep;29 (3 Suppl 1):97-100.

22. Wachtel H, Fickl S, Hinze M, Bolz W, Thalmair T. The bone lamina technique: a novel approach for lateral ridge augmentation-a case series. Int J Periodontics Restorative Dent 2013 Jul-Aug;33(4):491-497.

23. Khoury, F.; Khoury, $\mathrm{CH}$. Mandibular bone block grafts: diagnosis, instrumentation, harvesting techniques and surgical procedures. In: Khoury F, Antoun H, Missika P, editors. Bone Augment in Oral Implantology. Berlin: Quintessence; 2007.

24. Green J, Schotland S, Stauber DJ, Kleeman CR, Clemens TL. Cell-matrix interaction in bone: type I collagen modulates signal transduction in osteoblast-like cells. Am J Physiol 1995 May;268(5 Pt 1):C1090-C1103.

25. Baslé MF, Lesourd M, Grizon F, Pascaretti C, Chappard D. Type I collagen in xenogenic bone material regulates attachment and spreading of osteoblasts over the beta1 integrin subunit. Orthopade 1998 Feb;27(2):136-142.

26. Mizuno M, Fujisawa R, Kuboki Y. Type I collagen-induced osteoblastic differentiation of bone-marrow cells mediated by collagen-alpha2beta1 integrin interaction. J Cell Physiol 2000 Aug;184(2):207-213. 
27. Regazzoni C, Winterhalter $\mathrm{KH}$, Rohrer L. Type I collagen induces expression of bone morphogenetic protein receptor Type II. Biochem Biophys Res Commun 2001 May;283(2):316-322.

28. Güngörmüs M, Kaya O. Evaluation of the effect of heterologous Type I collagen on healing of bone defects. J Oral Maxillofac Surg 2002 May;60(5):541-545.

29. Liu G, Hu YY, Zhao JN, Wu SJ, Xiong Z, Lu R. Effect of Type I collagen on the adhesion, proliferation, and osteoblastic gene expression of bone marrow-derived mesenchymal stem cells. Chin J Traumatol 2004 Dec;7(6):358-362.

30. Gungormus M. The effect on osteogenesis of Type I collagen applied to experimental bone defects. Dent Traumatol 2004 Dec;20(6):334-337.

31. Toroian D, Lim JE, Price PA. The size exclusion characteristics of Type I collagen: implications for the role of noncollagenous bone constituents in mineralization. J Biol Chem 2007 Aug;282(31):22437-22447.
32. Perrotti V, Nicholls BM, Piattelli A. Human osteoclast formation and activity on an equine spongy bone substitute. Clin Oral Implants Res 2009 Jan;20(1):17-23.

33. Perrotti V, Nicholls BM, Horton MA, Piattelli A. Human osteoclast formation and activity on a xenogenous bone mineral. J Biomed Mater Res A 2009 Jul;90(1):238-246.

34. Artese L, Piattelli A, Di Stefano DA, Piccirilli M, Pagnutti S, D'Alimonte E, Perrotti V. Sinus lift with autologous bone alone or in addition to equine bone: an immunohistochemical study in man. Implant Dent 2011 Oct;20(5):383-388.

35. Di Stefano DA, Artese L, Iezzi G, Piattelli A, Pagnutti S, Piccirilli M, Perrotti V. Alveolar ridge regeneration with equine spongy bone: a clinical, histological, and immunohistochemical case series. Clin Implant Dent Relat Res 2009 Jun;11(2):90-100.

36. Di Stefano DA, Greco GB, Riboli F. Guided bone regeneration of an atrophic mandible with a heterologous bone block. Craniomaxillofac Trauma Reconstr 2016 Mar;9(1):88-93. 